\title{
PENINGKATAN PRODUKTIVITAS ALAT MUAT \\ (EX-1770) UNTUK PERCEPATAN PENGALIHAN SUNGAI TUNGKAL PT XYZ SITE AAA DENGAN PENDEKATAN QUALITY CONTROL CIRCLE
}

\author{
Tri Gamela Saldy ${ }^{1)}$ \\ ${ }^{1}$ Jurusan Teknik Pertambangan, Universitas Negeri Padang \\ email: trigamelasaldy@ ft.unp.ac.id
}

\begin{abstract}
Abstrak: PT.XYZ site AAA merencanakan percepatan pengalihan sungai tungkal. Apabila sungai tungkal tidak cepat dialihkan maka run off dari catchment area utara barat akan masuk kerencana lokasi penggalian BWE sehingga BWE tidak bisa beroperasi dan akan mengakibatkan cadangan batubara sebesar 1,2 juta ton tidak bisa diamankan. Apabila rencana pengalihan sungai tidak terealisasi makan PT.XYZ akan mengalami kerugian \pm 180.000 .000 USD (Rp 1,62 trilyun) dengan asumsi harga batubara dengan kualitas $5.900 \mathrm{Kkal}$ adalah sebesar USD 90 dan $1 \mathrm{USD}=\mathrm{Rp} 9000$. Produktivitas alat muat EX-1770 tidak tercapai atau sebesar $642 \mathrm{BCM} / \mathrm{Jam}$ dari target $680 \mathrm{BCM} / \mathrm{Jam}$. Penelitian ini bertujuan untuk meningkatkan produktivitas alat muat EX 1770 sehingga dapat memenuhi target produksi $300.000 \mathrm{BCM}$ pada bulan November. Metoda yang digunakan dalam penelitian ini adalah dengan menggunakan metoda Quality Control Circle (QCC) dengan pendekatan 8 Langkah Perbaikan. Dari hasil perbaikan dilapangan didapatkan kenaikan produktivitas EX-1770 adalah 692 BCM/Jam dari target 680 BCM/Jam.
\end{abstract}

Kata kunci: Produktivitas EX-1770, QCC, Sungai Tungkal, 8 Langkah Perbaikan

Abstract: PT. XYZ site AAA is planning to accelerate the diversion of tungkal river. If tungkal river is not diverted quickly, the run off of the north west catchment area will enter the BWE excavation site plan so that BWE cannot operate and will result in coal reserves of 1.2 million tons being unsecured. If the river diversion plan is not realized, PT.XYZ will incur a loss of $\pm 180,000,000$ USD (Rp. 1,62 trillion) assuming the price of coal with a quality of 5,900 Kcal is USD 90 and 1 USD $=R p$ 9,000. Productivity of EX-1770 loading equipment not reached or equal to 642 BCM / Hour from the target of 680 BCM / Hour. This study aims to increase the productivity of the EX 1770 loader so that it can meet the production target of 300,000 BCM in November. The method used in this research is to use the Quality Control Circle (QCC) method with an 8-Step Correction approach. From the results of improvement in the field, the EX-1770 productivity increase is $692 \mathrm{BCM} /$ Hour from the target of 680 BCM / Hour.

Keywords: Productivity EX-1770, QCC, tungkal river, 8 Steps for Improvement

\section{PENDAHULUAN}

Material sangat mempengaruhi produksi dan produktifitas dari peralatan. Material yang ada di site AAA sangat lunak, lembek sehingga material akan lengket divessel. Akibat faktor material yang

loose, lengket dan lokasi yang sempit PT $\mathrm{XYZ}$ site AAA menargetkan produktivity alat muat adalah sebesar $680 \mathrm{BCM} / \mathrm{jam}$. 
Produktivity EX-1770 aktual dilapangan adalah 642 BCM/Jam. Dalam kata lain produktivitas dari alat muat tidak tercapai dari rencana yang diharapkan (gambar 1).

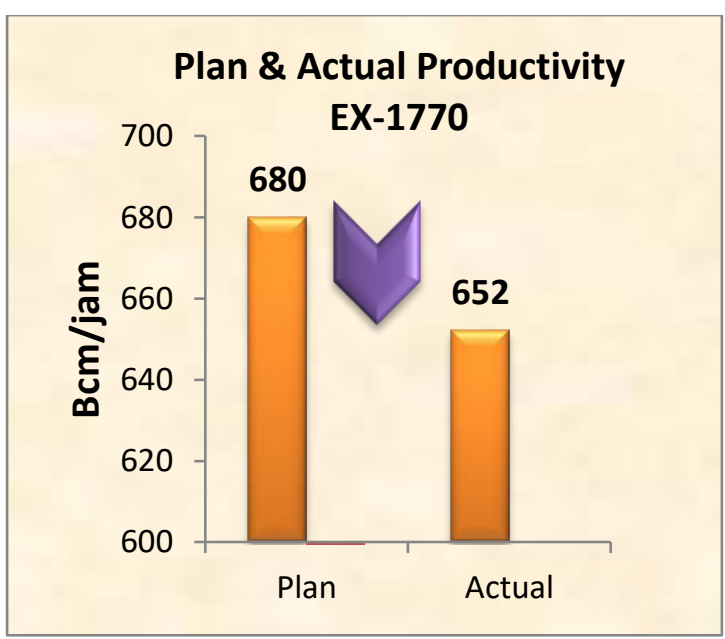

Gambar 1. Plan \& Actual Productivity EX1770

PT.XYZ site AAA merencanakan percepatan pengalihan sungai tungkal. Apabila sungai tungkal tidak cepat dialihkan maka run off dari catchment area utara barat akan masuk kerencana lokasi penggalian BWE, sehingga BWE tidak bisa beroperasi dan akan mengakibatkan cadangan batubara sebesar 1,2 juta ton tidak bisa diamankan. Apabila rencana pengalihan sungai tidak terealisasi maka PT.XYZ akan mengalami kerugian \pm 180.000.000 USD (Rp 1,62 trilyun) dengan asumsi harga batubara dengan kualitas $5.900 \mathrm{Kkal}$ adalah sebesar USD 90 dan 1 USD = Rp 9000.

Penelitian ini bertujuan untuk meningkatkan produktivitas alat muat EX 1770 sehingga dapat memenuhi target produksi 300.000 BCM pada bulan November.

Masalah yang utama dalam penurunan produktivitas EX-1770 adalah alat angkut kurang/ DT kurang, dapat dilihat pada diagram pareto di bawah ini.

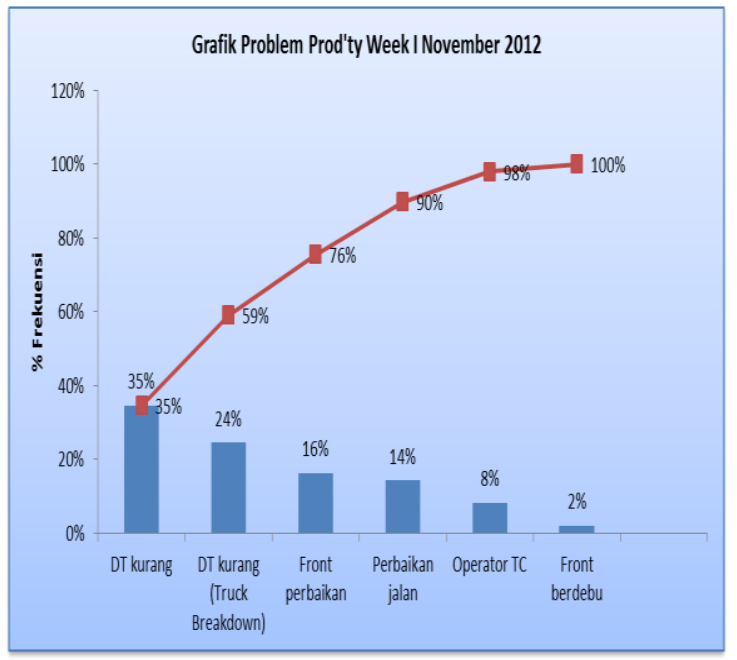

Gambar 2. Problem Produktivitas EX-1770

Terjadinya penurunan produktivitas alat muat pada gambar 2 di atas disebabkan oleh faktor sempitnya jalan pada spot-spot tertentu untuk menuju lokasi site AAA yang hanya bisa dilalui untuk 1 unit alat angkut. (Gambar 3).

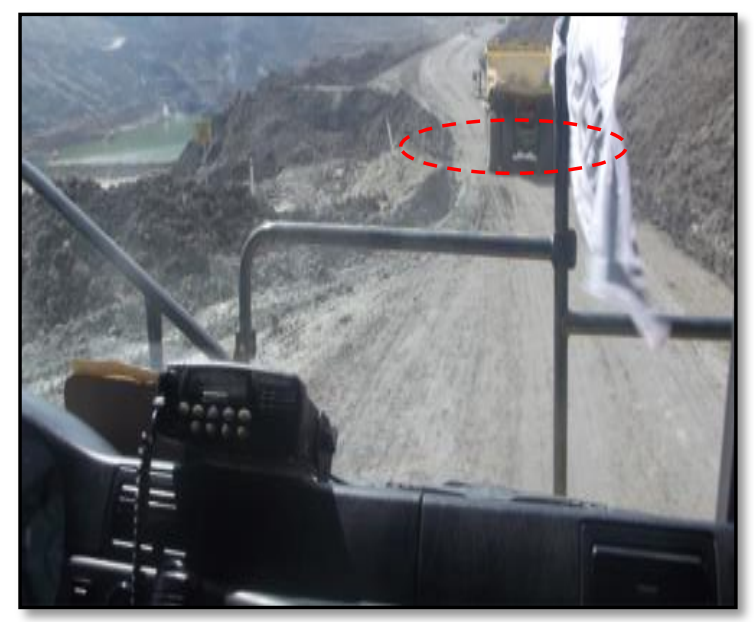

Gambar 3. Kondisi Jalan Angkut Menuju Site AAA

\section{METODE PENELITIAN}

Penelitian ini merupakan penelitian kuantitatif, karena penelitian ini menggunakan data numerik dan menekan proses penelitian pada pengukuran hasil objektif menggunakan analisis statistik. 
Penelitian ini menggunakan metode Quality Control Circle (QCC) dalam meningkatkan produktivitas alat muat EX1770.

QCC merupakan sistem pengendalian kualitas melalui metode 8 langkah dengan sistem perbaikan berkesinambungan atau kaizen.

Kaizen merupakan sebuah sistem perbaikan berkesinambungan atau terus menerus yang dilakukan pada ruang lingkup seperti : kualitas, teknologi, proses, budaya perusahaan, produktivitas, keselamatan dan kepemimpinan.

Dalam melakukan perbaikan menggunakan konsep PDCA (Plan - Do Check - Action). Kegiatan perbaikan dilakukan secara terus menerus dan berulang sampai mendapatkan hasil yang terbaik. Plan/rencana merupakan perencanaan yang baik/sesuai sebelum bekerja. Do/kerja merupakan pekerjaan/tindakan sesuai dengan rencana yang telah disusun. Check/periksa merupakan memeriksa hasil pekerjaan apakah telah sesuai dengan rencana. Action/aksi merupakan mengambil tindakan koreksi atau perbaikan atas penyimpangan yang ada kemudian susun rencana baru, seperti pada gambar 1 .

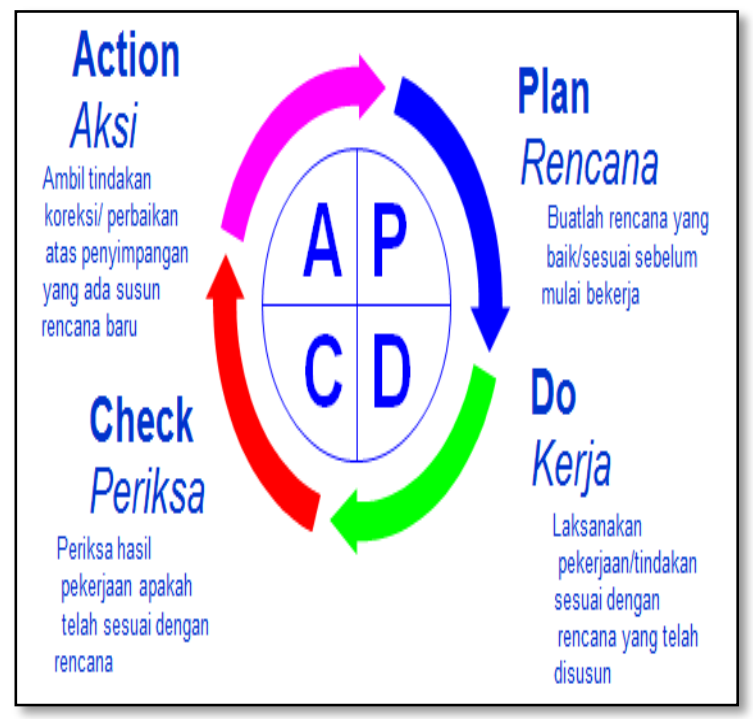

Gambar 4. Konsep PDCA
Delapan langkah perbaikan dapat dilihat pada gambar 5 di bawah ini:

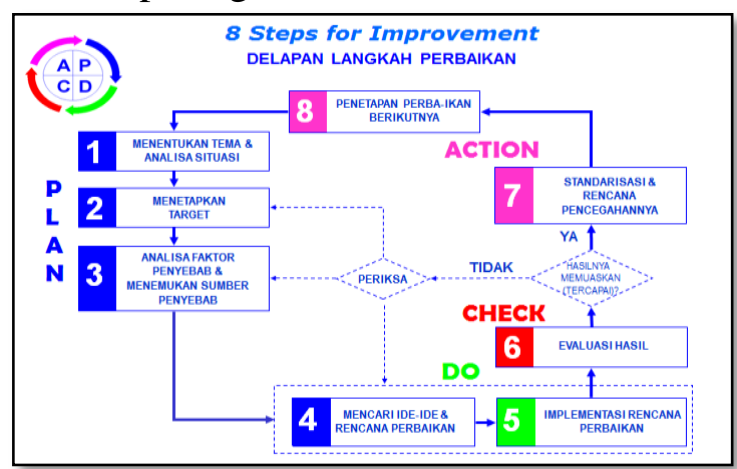

Gambar 5. Delapan Langkah Perbaikan

Delapan langkah perbaikan dalam sistem pengendalian kualitas dapat dilihat sebagai berikut:

1. Menentukan tema \& analisa situasi.

2. Menetapkan target.

3. Analisa faktor dan menemukan sumber penyebab.

4. Mencari ide-ide dan membuat rencana perbaikan.

5. Implementasi ide - ide perbaikan.

6. Evaluasi hasil.

7. Standarisasi dan rencana pencegahan.

8. Penetapan rencana berikutnya.

Tabel 1. Delapan Langkah Perbaikan

\begin{tabular}{|c|c|c|c|}
\hline STEPS & OBJECTIVES & $\begin{array}{l}\text { BASIC QC- } \\
\text { TOOLS }\end{array}$ & DELIVERABLE \\
\hline $\begin{array}{l}\text { Menentukan Tema dar } \\
\text { Analisa Situasi }\end{array}$ & $\begin{array}{l}\text { Memilh tema } \\
\text { ב Membentuk Tim QCC } \\
\text { ב Menentukan batasan QCC } \\
\text { ב Mengumpulkan data }\end{array}$ & $\begin{array}{l}\text { ב BRANSTORIIING } \\
\text { ב CHECK-SHEET } \\
\text { ב STRATIFICATION } \\
\text { ב PARETO } \\
\text { ב SCATTER } \\
\text { ב HISTOGRAII }\end{array}$ & $\begin{array}{l}\text { J Tema QCC } \\
\text { Tim QCC } \\
\text { Batasan Tema QCC } \\
\text { Data-data terkait dengan tema }\end{array}$ \\
\hline Menetapkan Target & $\begin{array}{l}\text { ב Menentukan kinerja saat ini } \\
\text { Menetapkan target kinerja }\end{array}$ & a. & $\begin{array}{l}\text { D Target perbaikan } \\
\text { Jiskripsi kondisi saat ini }\end{array}$ \\
\hline $\begin{array}{l}\text { Analisa Faktor dan } \\
\text { Menemukan Sumber } \\
\text { Penyebab }\end{array}$ & $\begin{array}{l}\text { ב Menentukan sumber } \\
\text { permasalahan } \\
\text { ב Menentukan sumber } \\
\text { permasalahan dominan }\end{array}$ & $\begin{array}{l}\text { ב BRANSTORIIING } \\
\square \text { FISHBONE } \\
\text { ב PARETO } \\
\text { ב SCATTER }\end{array}$ & $\begin{array}{l}\text { I Sumber-sumber penyebab } \\
\text { J Sumber penyebab dominan (root cause) }\end{array}$ \\
\hline $\begin{array}{l}\text { Mencari Ide-ide \& } \\
\text { Membuat Rencana } \\
\text { Perbaikan }\end{array}$ & $\begin{array}{l}\text { ב Mencari ide-ide perbaikan } \\
\text { (penaggulangan) } \\
\text { ב Memilh ide-ide perbaikan }\end{array}$ & $\mathrm{D}[5 \mathrm{~W} 2 \mathrm{H}]$ & $\begin{array}{l}\text { ב Sumber penyebab (WHAT), lokasi } \\
\text { (WHERE), alasan/lobyektif perbaikan } \\
\text { (WHY), ide-ide solusi terpilih (HOW), } \\
\text { biaya diperlukan (HOW HUCH), } \\
\text { penangoung-jawab (WHO), waktu } \\
\text { pelaksanaan (WHEN), }\end{array}$ \\
\hline $\begin{array}{l}\text { Implementasi Ide-ide } \\
\text { Perbaikan }\end{array}$ & $\begin{array}{l}\text { ב Implementasi ide-ide } \\
\text { perbaikan }\end{array}$ & ב. & $\square$ Diskripsi perbaikan \\
\hline Evaluasi Hasil & $\begin{array}{l}\text { I Memeriksa hasil perbaikan } \\
\text { (membandingkan sebelum } \\
\text { dan sesudah perbaikan) }\end{array}$ & $\begin{array}{l}\text { I CHECK-SHEET } \\
\text { a HISTOGRAM } \\
\text { a PARETO } \\
\text { ב CONTROL CHART }\end{array}$ & $\begin{array}{l}\text { D Diskripsi SEBELUUI dan SESUDAH } \\
\text { perbaikan }\end{array}$ \\
\hline $7 \int_{\text {Rencana Pencegahan }}^{\text {Standarisasi dan }}$ & $\begin{array}{l}\text { Dembuat standarisasi dan } \\
\text { rencana pencegahan }\end{array}$ & a. & $\begin{array}{l}\text { D BARU : Standard Operating Procedure } \\
\text { (SOP), Working Instruction (WI) }\end{array}$ \\
\hline 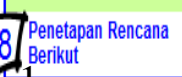 & $\begin{array}{l}0 \text { Menentukan rencana } \\
\text { perbaikan berikutnya }\end{array}$ & $\begin{array}{l}\text { D BRANSTROMING } \\
\text { a PARETO }\end{array}$ & Tema perbaikan berikutnya \\
\hline
\end{tabular}

Sumber: Modul 8 Langkah Perbaikan (PT. Pamapersada Nusantara) 


\section{HASIL DAN PEMBAHASAN}

Dalam penelitian ini menggunakan Anakonda Problem Productivity Loader \&

Hauler (gambar 6) dan Relation Ship Diagram (gambar 7), sehingga dapat memperbaiki permasalahan yang ada.

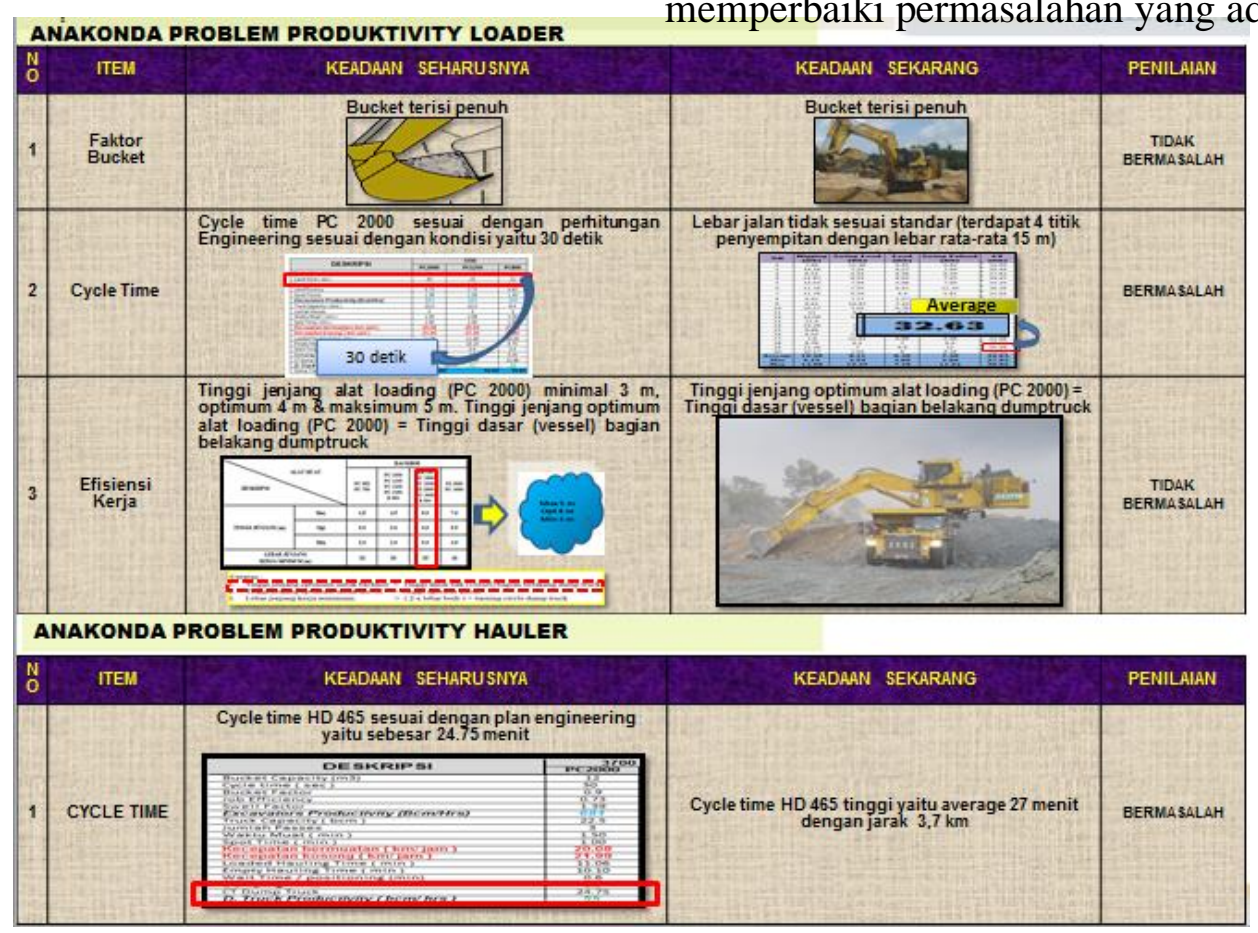

Gambar 6. Anakonda Problem Productivity Loader \& Hauler

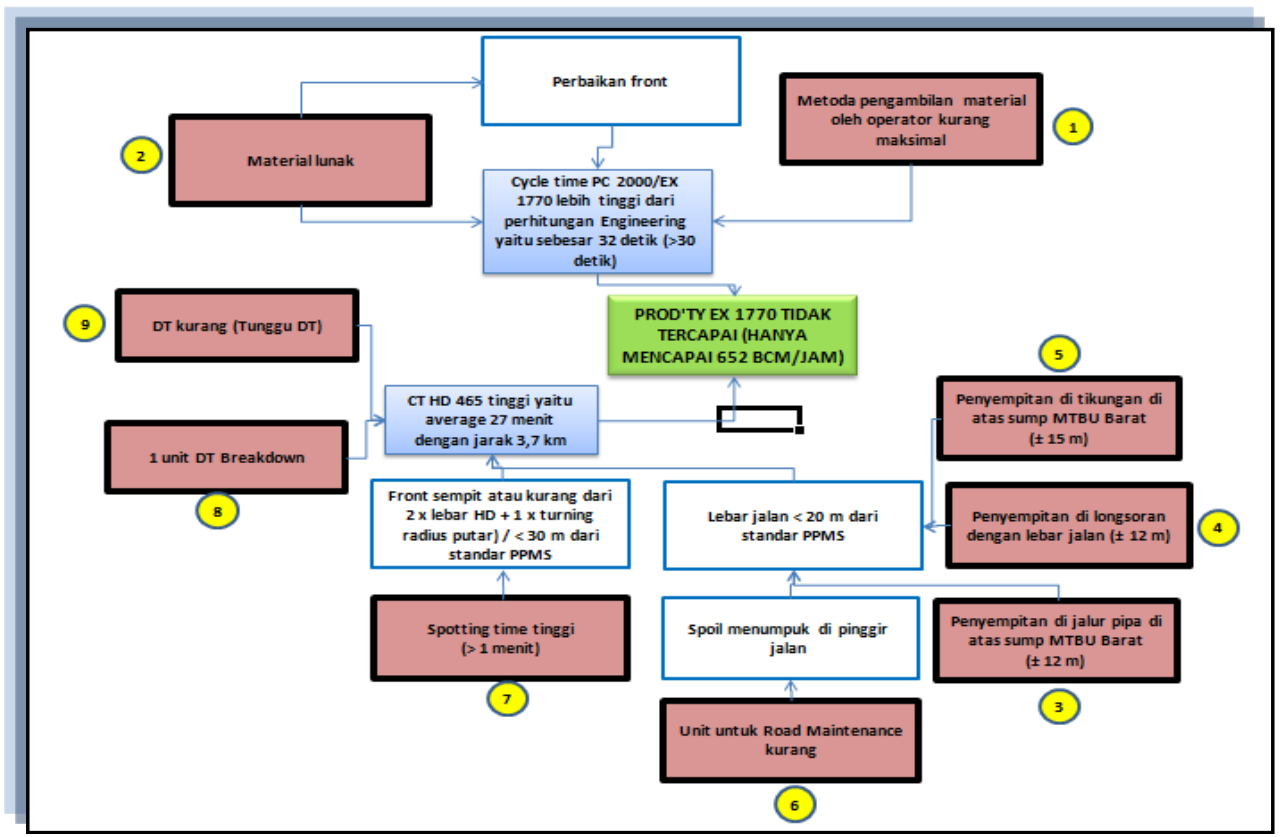

Gambar 7. Relation Ship Diagram

Dapat terlihat pada gambar $7 \mathrm{di}$ atas bahwasanya ada 9 akar penyebab masalah produktivitas alat muat EX-1770 tidak tercapai (hanya $652 \mathrm{BCM} / \mathrm{Jam}$ ).
9 akar penyebab masalah akan dilakukan validasi akar penyebab masalah oleh pengawas lapangan yang sesuai dengan bidangnya. 
Langkah selanjutnya adalah mencari ide penyebab masalah dengan sistem $5 \mathrm{~W}+1$ H (What, Why, When, Where, Who, How) ide dan rencana perbaikan dari akar (Tabel 2).

Tabel 2. Mencari Ide - Ide dan Rencana Perbaikan

\begin{tabular}{|c|c|c|c|c|c|c|c|c|c|}
\hline \multirow{3}{*}{ No } & WHAT & HOW & WHY & \multirow{3}{*}{ Efektifitas } & \multirow{2}{*}{ When } & \multirow{2}{*}{ Where } & \multirow{2}{*}{ Who } & \multirow{2}{*}{ Conclusion } & \multirow{3}{*}{$\begin{array}{l}\text { How } \\
\text { Much }\end{array}$} \\
\hline & \multirow{2}{*}{ Root Cause } & \multirow{2}{*}{ Rencana Perbaikan } & \multirow{2}{*}{ Kemudahan } & & & & & & \\
\hline & & & & & Due Date & Lokasi & PIC & Kesimpulan & \\
\hline 1 & $\begin{array}{l}\text { Metoda } \\
\text { pengambilan } \\
\text { oleh operator } \\
\text { kurang } \\
\text { maksimal }\end{array}$ & $\begin{array}{l}\text { Memberikan pengarahan \& } \\
\text { pendampingan pada operator } \\
\text { cara kerja yang benar yang } \\
\text { dilakukan oleh instruktur } \\
\text { selama 1 ajm }\end{array}$ & $\begin{array}{l}\text { Mudah, dapat } \\
\text { dilakukan dengan } \\
\text { cepat (meningkatkan } \\
\text { skill operator) }\end{array}$ & Efektif & November & $\begin{array}{l}\text { Site } \\
\text { AAA }\end{array}$ & Prod \& OTD & Dipilih & - \\
\hline 2 & $\begin{array}{l}\text { Material } \\
\text { lunak } \\
\text { (perbaikan } \\
\text { front) }\end{array}$ & $\begin{array}{l}\text { Dozer melayani loader untuk } \\
\text { perbaikan front }\end{array}$ & $\begin{array}{l}\text { Mudah, dapat } \\
\text { dilakukan dengan } \\
\text { cepat }\end{array}$ & Efektif & November & $\begin{array}{l}\text { Site } \\
\text { AAA }\end{array}$ & Produksi & Dipilih & - \\
\hline \multirow[b]{2}{*}{3} & \multirow{2}{*}{$\begin{array}{l}\text { Penyempitan } \\
\text { di longsoran } \\
\text { dengan lebar } \\
\text { jalan }( \pm 12 \\
\text { m) }\end{array}$} & $\begin{array}{l}\text { Pelebaran jalan dengan } \\
\text { penambahan gorong-gorong }\end{array}$ & Susah & $\begin{array}{l}\text { Tidak } \\
\text { efektif }\end{array}$ & November & $\begin{array}{l}\text { Site } \\
\text { AAA }\end{array}$ & Customer & $\begin{array}{c}\text { Tidak } \\
\text { Dipilih }\end{array}$ & $\begin{array}{c}\mathrm{Rp} \\
10.000 .000\end{array}$ \\
\hline & & $\begin{array}{l}\text { Memasang rambu prioritas \& } \\
\text { melakukan komunikasi } \\
\text { menggunakan radio untuk } \\
\text { muatan lebih diprioritaskan }\end{array}$ & $\begin{array}{l}\text { Mudah, dapat } \\
\text { dilakukan dengan } \\
\text { cepat }\end{array}$ & Efektif & November & $\begin{array}{l}\text { Site } \\
\text { AAA }\end{array}$ & Produksi & Dipilih & - \\
\hline \multirow{2}{*}{4} & \multirow{2}{*}{$\begin{array}{l}\text { Penyempitan } \\
\text { di jalur pipa } \\
\text { di atas sump } \\
\text { MTBU Barat }\end{array}$} & $\begin{array}{l}\text { Melakukan pelebaran pada jalur } \\
\text { pipa di atas pompa MTBU } \\
\text { Barat dengan melakukan } \\
\text { penambahan pia }\end{array}$ & $\begin{array}{l}\text { Tidak bisa dilakukan } \\
\text { (slope sudah final) }\end{array}$ & $\begin{array}{l}\text { Tidak } \\
\text { efektif }\end{array}$ & November & $\begin{array}{c}\text { Site } \\
\text { AAA }\end{array}$ & Customer & $\begin{array}{l}\text { Tidak } \\
\text { Dipilih }\end{array}$ & $\begin{array}{c}\mathrm{Rp} \\
6.000 .000\end{array}$ \\
\hline & & $\begin{array}{l}\text { Memasang rambu prioritas \& } \\
\text { melakukan komunikasi melalui } \\
\text { radio pada driver untuk muatan } \\
\text { lebih diprioritaskan }\end{array}$ & $\begin{array}{l}\text { Mudah, dapat } \\
\text { dilakukan dengan } \\
\text { cepat }\end{array}$ & Efektif & November & $\begin{array}{c}\text { Site } \\
\text { AAA }\end{array}$ & Produksi & Dipilih & - \\
\hline 5 & $\begin{array}{l}\text { Penyempitan } \\
\text { di tikungan } \\
\text { di atas sump } \\
\text { MTBU Barat } \\
( \pm 15 \mathrm{~m})\end{array}$ & $\begin{array}{l}\text { Melakukan pelebaran jalan } \\
\text { dengan melakukan pemindahan } \\
\text { tanggul/ penggeseran tanggul } \\
\text { menggunakan DZ } 85\end{array}$ & $\begin{array}{l}\text { Mudah, dapat } \\
\text { dilakukan dengan } \\
\text { cepat }\end{array}$ & Efektif & November & $\begin{array}{c}\text { Site } \\
\text { AAA }\end{array}$ & Produksi & Dipilih & $\begin{array}{c}\mathrm{Rp} \\
638.400\end{array}$ \\
\hline 6 & $\begin{array}{l}\text { Unit road } \\
\text { maintenance } \\
\text { kurang }\end{array}$ & $\begin{array}{l}\text { Pembuatan shelter-shelter untuk } \\
\text { spoil dengan menggunakan DZ } \\
85\end{array}$ & $\begin{array}{l}\text { Mudah, dapat } \\
\text { dilakukan dengan } \\
\text { cepat }\end{array}$ & Efektif & November & $\begin{array}{c}\text { Site } \\
\text { AAA }\end{array}$ & Produksi & Dipilih & $\begin{array}{c}\mathrm{Rp} \\
7.341 .600\end{array}$ \\
\hline \multirow[b]{2}{*}{7} & \multirow{2}{*}{$\begin{array}{l}\text { Spotting time } \\
\text { tinggi }>1 \\
\text { menit) }\end{array}$} & $\begin{array}{l}\text { Melakukan pelebaran front, } \\
\text { berkomunikasi terlebih dahulu } \\
\text { dengan Engineering }\end{array}$ & $\begin{array}{l}\text { Susah (tidak bisa } \\
\text { dilebarkan lagi) }\end{array}$ & $\begin{array}{l}\text { Tidak } \\
\text { efektif }\end{array}$ & November & $\begin{array}{l}\text { Site } \\
\text { AAA }\end{array}$ & Customer & $\begin{array}{c}\text { Tidak } \\
\text { Dipilih }\end{array}$ & - \\
\hline & & $\begin{array}{l}\text { Mengatur komunikasi melalui } \\
\text { radio oleh GL Produksi dengan } \\
\text { DT bermuatan lebih } \\
\text { diprioritaskan }\end{array}$ & $\begin{array}{l}\text { Mudah, dapat } \\
\text { dilakukan dengan } \\
\text { cepat }\end{array}$ & Efektif & November & $\begin{array}{c}\text { Site } \\
\text { AAA }\end{array}$ & Produksi & Dipilih & - \\
\hline 8 & $\begin{array}{l}\text { DT } \\
\text { Breakdown }\end{array}$ & Penambahan DT dari PIT lain & Tidak bisa dilakukan & $\begin{array}{c}\text { Tidak } \\
\text { Efektif }\end{array}$ & November & $\begin{array}{c}\text { Site } \\
\text { AAA }\end{array}$ & Produksi & $\begin{array}{c}\text { Tidak } \\
\text { Dipilih }\end{array}$ & - \\
\hline 9 & $\begin{array}{l}\text { DT kurang } \\
\text { (Tunggu DT) }\end{array}$ & $\begin{array}{l}\text { Memaksimalkan kecepatan DT } \\
\text { dengan cara melakukan } \\
\text { pelebaran jalan \& loading spoil }\end{array}$ & $\begin{array}{l}\text { Mudah, dapat } \\
\text { dilakukan dengan } \\
\text { cepat }\end{array}$ & Efektif & November & $\begin{array}{c}\text { Site } \\
\text { AAA }\end{array}$ & Produksi & Dipilih & - \\
\hline
\end{tabular}

Setelah ide - ide dan rencana perbaikan didapatkan, maka langsung diimplementasikan dilapangan untuk diselesaikan sehingga dapat memenuhi target produktivitas dari muat.

Hasil dari implementasi dari rencana perbaikan $1 \& 2$ didapatkan bahwa cycle time dari alat muat jadi turun dari 32,63 detik menjadi 28,17 detik.

Untuk implementasi perbaikan $3 \& 4$ maka dilakukan pemasangan rambu dan mengatur komunikasi antara driver dengan group leader sehingga driver lebih konsisten terhadap prioritas jalur muatan. 
Untuk implementasi perbaikan 5 \& 6 maka dilakukan pelebaran jalan pada titik Penyempitan dengan melakukan pemindahan tanggul sehingga jalan menjadi lebar. Kemudian membuat shelter untuk spoil - spoil yang berserakan.

Pada implementasi $7 \& 9$ didapatkan spotting time turun sebesar 10,64\%. Cycle time alat angkut dari 26,73 menit menjadi 24,66 menit, dan meningkatkan kecepatan DT dari rata-rata $16,99 \mathrm{~km} / \mathrm{jam}$ menjadi $19 \mathrm{~km} / \mathrm{jam}$.

Dari perbaikan yang dilakukan diperoleh kenaikan produktivitas EX-1770 dari 652 BCM/Jam menjadi 692 BCM/Jam yang artinya lebih besar dari target yang ditetapkan sebesar 680 BCM/Jam.

\section{KESIMPULAN}

Berdasarkan hasil penelitian yang dilakukan dapat disimpulkan bahwa terjadi peningkatan produktivitas EX-1770 dari $652 \mathrm{BCM} / \mathrm{Jam}$ menjadi $692 \mathrm{BCM} / \mathrm{Jam}$ yang artinya lebih besar dari target yang ditetapkan sebesar $680 \mathrm{BCM} / \mathrm{Jam}$.

Pengalihan Sungai Tungkal dapat dialihkan sesuai dengan target yang ditetapkan sehingga run off dari catchment area utara barat tidak masuk kerencana lokasi penggalian BWE sehingga BWE bisa beroperasi dan cadangan batubara sebesar 1,2 juta ton bisa diamankan.

\section{DAFTAR PUSTAKA}

Nuryono, A., Sjarifudin, D., \& Ahmad, Q. (2016). Peningkatan Produktivitas Alat Muat Sekelas Oht Cat 777 Di Pertambangan Batubara Dengan Pendekatan Quality Control Circle. Jurnal Teknik Industri, 6(2).

PT. Pamapersada Nusantara, 2012, Modul Pelatihan New QC For Leader, Palembang. 